*BEST AVOIDED

\section{Renal stones}

ILYAS ARSHAD, KA SHAR-BALOCH

Pilgrim Hospital, Boston, Lincs, UK

\section{University of Maryland Medical Center}

http://www.umm.edu/patiented/articles/

what_procedures_treating_kidney_stones_000081_10.htm

Produced by the University of Maryland Medical Center, this site has been professionally constructed. Packed with useful information and statistics to justify most of the statements made, it is mostly text-based but has some pictorial representations to explain renal stone disease. On offer are general guidelines in the management of renal stones. It is a very precise website, as one would expect. Occasionally, it delves into greater detail, i.e. in explaining which treatment method is best to remove a particular type of stone, depending on its size, consistency and position. Like most sites, dietary and life-style advice is provided in an attempt to prevent recurrent renal stone disease.****

\section{E-Radiography}

\section{http://www.e-radiography.net/xray2000homepage.htm}

This site is run by a dedicated radiographer named Nicholas Oldnall, a senior superintendent at Gloucestershire Royal Hospital. Within the archives are thousands of X-ray images collected over the years. It has been well put together and there is something here for everybody. I am sure all the radiography and radiology students have this website on their favourites page. It shows common and rare images that cover most specialities, including urology, vascular, orthopaedics, general surgery and ENT. The urology section has over 100 images. These are a useful educational tool and a useful resource when delivering presentations. In addition, there is a section on interview tips and also brushing up your curriculum vitae. ***

\section{Bard Urology Site}

\section{http://www.bardurological.com/Patient/}

what_you_should_know.aspx?bunit10=3

Bard is responsible for producing equipment useful in endourology as well as in other disciplines such as vascular surgery. This is primarily a commercial site, which also contains a section on renal stone disease. This section is quite useful in explaining the overview of the disease and the treatment options available. The FAQ section is particularly useful.**

\section{Hollywood Urology}

\section{http://www.hollywoodurology.com/stones.html}

Although sceptical about the name of this website, it is a good site run by an American urologist. It explains treatment options very well, with the aid of some dubious diagrams. These give the site a dated look, although the actual written content more than makes up for the presentation. It covers renal stone disease particularly well. There is a section on the different types of stones, symptoms, treatments and also some advice on preventative measures. ${ }^{* * * *}$

\section{Urology Health \\ http://www.urologyhealth.org/adult/ \\ index.cfm?cat $=12 \&$ topic $=132 \& \mathrm{x}=14 \& \mathrm{y}=11$}

A 'no-thrills' site that covers the basics well. It is methodical and includes sections on various types of renal stones, symptoms and the various medical and surgical treatment options available. This site is suitable to recommend to patients who wish to read about their disease. Easy to understand, the content is correct and not controversial. **

\section{American Urology Corp}

http://www.wramc.amedd.army.mil/deparments/surgery/urology/urs.htm This US military website has been included as it understands the importance of preventative strategies in avoiding renal stone disease. It suggests that drinking 8-10 8-0z glasses of fluid a day is useful in countering the formation of renal stones. However, it does not explain where it obtained this figure - a few gaps in explanation are the prerogative of the US Army. The best features of the website are the diagrammatic representations and explanations of procedures such as ESWL, PCNL, stenting, ureteroscopy and cystolithopaxy. This section is accurate and informative to both patients and clinicians. ${ }^{* * *}$

\section{Stenosing tenosynovitis (trigger finger and trigger thumb)}

\section{SONNA N IFEACHO, RANJEET BRAR}

Northwick Park Hospital, Harrow, Middlesex, UK

\section{CORRESPONDENCE TO}

Sonna N. Ifeacho, Northwick Park Hospital, Harrow, Middlesex, UK E: sifeacho@hotmail.com

Trigger finger (or thumb) arises either from thickening of the flexor tendon sheath (which occurs following tenosynovitis of infective, traumatic or rheumatolgical origin) or from nodular thickening of the flexor tendon itself which may be congenital. In either case, smooth passage of the tendons through their sheaths is compromised, causing symptoms of delayed and sometimes painful extension of the digit (commonly the middle finger), perhaps accompanied by a cracking sound. Patients commonly report having to straighten the finger physically, which otherwise remains locked in the flexed position. It is associated with several systemic conditions including diabetes and rheumatoid arthritis, but is also related to repetitive strain injuries. When seen in industrialised countries whose populace spend many hours a week playing video games and using mobile phones to send text messages it has been dubbed 'texting tendonitis', to which we might add 'Game-Boy thumb'! The prevalence of this condition may rise with increasing use of mobile phones and games' consoles. Below, we review web sites currently available as learning resources for clinicians and patients. 


\section{http://www.mayoclinic.com/health/trigger-finger/DS00155/ DSECTION=1}

This is a website run by the Mayo Clinic - an umbrella institution for three American hospitals which focuses on research and education. As would be expected, the content is excellent. There is an introductory overview of the condition, details of its signs and symptoms, causes and risk factors and the various means of management of trigger finger. There is a printer-friendly version and the facility to read the article in a larger text format. There is, however, only one annotated image accompanying the lengthy text. Though insufficient in anatomical and surgical detail for a medical student or health professional, it is an excellent site for patients suffering from trigger finger. ${ }^{* * *}$

\section{http://www.handuniversity.com/topics.asp?Topic_ID=28}

This website is associated with an American orthopaedic group, the Colorado Springs Orthopaedic Group. It is written by several medical doctors and is aimed at patients. It has good structure and layout and uses simple language that is easy to understand. There are good pop-up diagrams that show the structures of the digits and how these structures are involved in the pathophysiology of trigger finger. It explains how the condition arises, what causes the symptoms and the treatment options available including the role of physiotherapy. There is a diagram showing a steroid injection and there is also an animation of surgery to release the trigger finger.****

\section{http://www.emedicine.com/orthoped/topic571.htm}

This website has a comprehensive content that covers numerous medical conditions. This is a well laid-out site that logically covers all aspects of trigger finger. The language used is clear enough for the lay person, but the more technical terms used make for better understanding for the medical student and professional. There is use of colour photography to demonstrate the steps involved in surgical treatment of trigger thumb. The article concludes with a brief bibliography. Some added bonuses of the site are that it states when the review article was last updated and the useful facility of directly e-mailing the article from the website. ${ }^{* * *}$

\section{http://orthoinfo.aaos.org/fact/thr_report.cfm? \\ Thread_ID=168\&topcategory=Hand}

This site is run by the American Association of Orthopedic Surgeons and is written by hand specialists. It is a very concise account of trigger finger, but within its short narrative conveys the essentials of the condition and its management. The targeted audience is more patient than professional. There is a distinct lack of diagrams and a solitary photograph of a finger in fixed flexion is a poor effort. One can e-mail this article directly and there is a printer-friendly version. It is possible to give feedback on one's view of the article and this will hopefully serve to improve the site.** http://www.wheelessonline.com/ortho/trigger_finger_tenosynovitis This website, which is an online orthopaedic textbook, is an indispensable resource for orthopaedic surgeons and yet again comes up trumps for information. It has an up-to-date overview of the trigger finger. The content of the site is excellent with intricate diagrams detailing the anatomical structures of the digits. Quoted references are identified for specific sections such as the treatment of trigger finger and there are links that take the reader straight to the paper's details or even an abstract of the quoted paper. There are clear, colour photographs of operative management. Throughout the article, there are good links to other parts of the website for more information on more specific points. ${ }^{* * * *}$

\section{http://www.pncl.co.uk/ belcher/trigger.htm}

This is a website run by a consultant in plastic surgery based at the Queen Victoria Hospital, East Grinstead, UK. It gives a brief summary of trigger finger with the main emphasis on management. It is mainly directed at patients that are under his care, but there is useful information here that is of relevance to all affected by trigger finger. There is good use of animated diagrams; however, it is the series of clear, close-up, colour photographs of surgery that will be of interest to those surgical trainees that will be performing this procedure. There is an accompanying PDF information sheet.***

\section{http://www.patient.co.uk/showdoc/23069103/}

This website is written by UK general practitioners and is aimed at the patient population. It has a succinct summary of trigger finger including treatment options. There are a couple of diagrams to aid explanation. A leaflet can be downloaded.**

\section{http://www.assh.org/Content/NavigationMenu/PatientsPublic/} HandConditions/TriggerFingerStenosingTenosynovitis/Trigger_Finger.htm This is another American site run by the American Society for Surgery of the Hand. The site contains overviews of many conditions affecting the hand. The target audience is patient and public; however, the content can also serve as a basic introduction to the condition for the student population. There is an accompanying down-loadable PDF.**

\section{http://www.themediweb.net/orthopaedics/infosheets_html/ inpatients/Trigger\%20Finger\%20Adult.htm\#}

This site is written for, and run by, medical professionals. The article on trigger finger is a patient information leaflet and deals mainly with the details of operative management with a brief partial explanation of the aetiology of trigger finger. The emphasis is on explaining what the operative procedure entails and the practicalities of having it done. There are some very good animated diagrams of how a normal finger flexes and extends and how a finger 'triggers' due to nodular swelling of the tendon. It then goes on to illustrate, again by animation, how the tendon sheath is divided to allow free movement of the tendon. ${ }^{* *}$ 